\title{
A CONCORDÂNCIA VERBAL COM A PRIMEIRA PESSOA DO PLURAL EM PANAMBI E PORTO ALEGRE, RS
}

\author{
Ana Maria Stahl Zilles, \\ Leonardo Zechlinski Maya e Karine Quadros da Silva
}

\begin{abstract}
RESUMO: This is part of a project about several related morphosyntactic changes in Brazilian Portuguese using data from VARSUL data base. Two cities in RS are considered: Porto Alegre, the capital, and Panambi, a bilingual community. The sample included 32 interviews stratified according to sex, age, and level of formal education. The variable investigated is verbal marking with first person plural subjects. The variants are: standard agreement (-mos ending) and two nonstandard forms: zero and /s/deleted -mo inflections. Supposing two different variable rules, we made three separate Varbrul analyses: a) contrasting the three variants; b) contrasting zero inflection with both -mos and -mo endings taken together; and c)contrasting only -mos and -mo endings. The distribution of the variants was: $53 \%$ of standard tokens, $34 \%$ of -mo endings and only $13 \%$ of zero inflection. Results showed different factor groups associated with zero inflection and nonstandard -mo inflection, supporting the idea of having two separate variable rules. The level of formal education turned out to be the only significant factor group in common for both nonstandard forms. It was also highlighted in the three-way comparison. Zero inflection was favoured only when the target word had antepenultimate stress, suggesting avoidance of this stress pattern. The bilingual community had an effect only on zero inflection.
\end{abstract}

PALAVRAS-CHAVE: concordância verbal, variação, mudança, sociolingüística

\footnotetext{
Ana Maria Stahl Zilles é professora da UFRGS.

Leonardo Zechlinski Maya é aluno do Bacharelado em Letras/UFRGS bolsista de Iniciação Científica voluntário junto ao Projeto Varsul ( 98-2000).

Karine Quadros da Silva é aluna da Licenciatura em Letras/UFRGS ,bolsista de Iniciação Científica da PROPESQ/UFRGS ( 98-99) e PIBIC/CNPq (2000-2001)
} 


\section{INTRODUÇÃO}

O objetivo deste artigo é apresentar resultados parciais de um estudo em que se investiga, nos dados do Projeto Variação Lingüística Urbana na Região Sul - VARSUL -, a variação na concordância verbal com a primeira pessoa do plural (P4), considerando a língua falada em duas comunidades do Rio Grande do Sul, Panambi e Porto Alegre. Inicialmente, apresentamos a revisão da literatura, segundo a qual a concordância verbal deve ser tratada como regra variável no português do Brasil. A seguir, vêm as hipóteses e questões discutidas neste estudo e a metodologia utilizada para realizá-lo. Seguem-se a apresentação e discussão dos resultados desta fase da investigação e a conclusão.

\section{A CONCORDÂNCIA VERBAL COMO REGRA VARIÁVEL}

No português padrão, a concordância verbal em termos de desinência número-pessoal (DNP) é considerada regra categórica. No entanto, muitas são as investigações que demonstram que, nas variedades não-padrão do português do Brasil, a concordância verbal precisa ser definida como regra variável.

As investigações já realizadas se concentraram principalmente na presença/ausência de marca de terceira pessoa do plural (P6), tendo demonstrado variação na concordância verbal ao longo de todo o continuum dialetal brasileiro ${ }^{1}$. Um dos extremos desse continuum é representado pela fala em situações de contato, como no Xingu (EMMERICH, 1984), e de crioulização prévia, como em Helvécia (BAXTER, 1992 e 1995). Nessas situações predomina o uso da forma básica do verbo (radical + vogal temática), sem desinência número-pessoal, e os falantes estão iniciando a aquisição do sistema de marcas de pessoa. A seguir, há o dialeto rural (ASSIS, 1988), em que a diferenciação é feita marcando-se apenas a primeira pessoa do singular (P1). Passa-se, então, aos dialetos resultantes do intenso movimento migratório e do êxodo rural (BORTONI-RICARDO, 1985) e aos dialetos populares dos grandes centros urbanos, conforme dados de alunos do Projeto MOBRAL no Rio de Janeiro (GUY, 1981) e dados de favelados da periferia de São Paulo (RODRIGUES, 1992), em que ocorre variação em P4 (canta/cantamos) e em P5 e P6 (canta/cantam). No outro extremo do continuum oral, encontra-se o dialeto culto, caracterizado por dados de São Paulo do Projeto NURC (CAMACHO, 1993), em que há pequena variação no emprego das desinências.

A ausência de marca da terceira pessoa do plural ou o seu emprego indevido também têm sido relatados em investigações sobre a língua escrita. Este é o caso do valioso artigo em que Mattoso Camara (CAMARA JR.,1972, p.35-46) analisa "erros" em redações escolares os considera como indicativos de tendências da língua falada. Dentre tais "erros", o autor observou uma tendência a não se

\footnotetext{
${ }^{1}$ Consideramos a noção de continuum dialetal conforme Bortoni (1984).
} 
aplicar a regra de concordância quando o sujeito se apresenta posposto ao verbo (1). Por outro lado, certas ocorrências também mostram que as crianças podem fazer a concordância verbal com o complemento de lugar (2), como termo que antecede ao verbo:

(1) "mais adiante no matagal pastava os bois e cavalos"

(2) "nas duas margens crescem relva abundante"

Quanto à concordância de primeira pessoa do plural, Mattoso Camara Jr. (1972) apenas comenta que as crianças usam, em suas redações, a desinência -mos grafada com hífen, como se fosse contração pronominal (3), nos casos de verbos no infinitivo flexionado:

(3) “descrever-mos, contar-mos, etc."

Veremos, adiante, que essas tendências anotadas por Mattoso Camara Jr. são, de fato, bem gerais na fala e recorrentes na escrita de estudantes.

Dentre as investigações que, em maior ou menor grau, tratam, especificamente, da variação na concordância com primeira pessoa do plural, salientamos os seguintes. Assis (1988) descreve brevemente o sistema de concordância verbal do dialeto rural, mostrando que não há desinência de primeira pessoa do plural. Bortoni-Ricardo (1985, p.210-215) trata a variação na cidade satélite de Brazlândia como aquisição da regra de concordância de $1^{\mathrm{a}}$. pessoa do plural $^{2}$ por migrantes que mudaram da zona rural para a zona urbana. Rodrigues (1992) investiga a concordância na fala popular da periferia de São Paulo, com falantes analfabetos ou semi-escolarizados. E Naro et al. (1999) investigam a concordância de P4 com sujeito nós ou a gente na fala da cidade do Rio de Janeiro. Vejamos os pontos mais importantes desses trabalhos.

Em sua tese sobre a urbanização de falantes de dialeto rural, BortoniRicardo $(1985$, p.211) registra, para a primeira pessoa do plural, além da forma padrão, três formas variantes, com a seguinte caracterização:

"O sufixo de primeira pessoa do plural -mos - /mus/ na língua padrão —, pode se realizar como $/ \mathrm{mu} /$ ou ser simplesmente apagado. Neste último caso a forma não-marcada não-primeira pessoa ${ }^{3}$ é usada em seu lugar. No dialeto Caipira a variante $/ \mathrm{mu} /$ geralmente co-ocorre com uma mudança da vogal temática (/a/ >

\footnotetext{
${ }^{2}$ A autora trata também do emprego da desinência de $3^{\text {a }}$. pessoa do plural.

${ }^{3}$ Bortoni-Ricardo (1985, p.211) caracteriza a forma como "unmarked nonfirst" - não-marcada nãoprimeira pessoa em função de que o sistema de concordância não apresenta seis desinências diferentes, e sim quatro, assim caracterizadas: primeira pessoa e não-primeira pessoa do singular; primeira pessoa e não-primeira pessoa do plural.
} 
(e/) nos pretéritos ${ }^{4}$ da primeira conjugação" como em nós falamos versus nós falemu.

Sua análise é binária, contrastando omissão versus manutenção da DNP-P4 $(\text { seja }-m o s \text { ou }-m o)^{5}$. Em termos gerais, Bortoni-Ricardo (1985, p.213) obteve 56\% (685/1224) de aplicação da regra de concordância, ou seja, de presença de DNPP4. Os grupos de fatores significativos nessa análise foram os seguintes:

a) posição do acento - nas proparoxítonas houve somente $10 \%$ de manutenção da DNP-P4, contra $62 \%$ nas paroxítonas; a autora considera esse resultado esperado, dada a produtividade, nesse dialeto, de uma regra fonológica de apagamento de sílaba átona final que afeta as palavras proparoxítonas;

b) posição do sujeito - sujeito nulo foi o fator mais favorecedor, com $84 \%$ (260/310) de realização da DNP-P4; o sujeito anteposto adjacente (até 5 sílabas de material interposto), com 47\% (417/888); sujeito anteposto distante, com 34\% (4/12); e sujeito posposto, com 29\% (4/14);

c) sexo - os homens tiveram $66 \%(473 / 719)$ de DNP-P4 e as mulheres, $42 \%$ (212/505); a autora explica a diferença entre homens e mulheres no controle da regra de concordância como resultante de diferenças no processo de ajustamento ao seu novo ambiente, em que os homens lideravam a transição rural-urbano (p. 213), enquanto para as mulheres (p.215), o processo de aquisição da DNP-P4 estava menos avançado; excepcionalmente, as 4 mulheres que apresentaram índices mais altos estavam muito expostas a interações com jovens (seus filhos e seus amigos) em casa, adquirindo com esse contato maior controle no uso da DNP-P4;

d) idade - os jovens apresentaram 82\% (244/298) de DNP-P4, e os adultos, $48 \%$ (441/926), indicando maior integração dos jovens à cultura urbana de seu novo ambiente.

Rodrigues (1992) investigou a língua popular falada na periferia de São Paulo (Zona Oeste, Carombé) por informantes que pertenciam a uma comunidade de favelados, constituída por analfabetos ou semi-escolarizados. No artigo aqui considerado, a autora discute a variação na concordância verbal de $1^{\mathrm{a}}$. e $3^{\mathrm{a}}$. pessoas do plural. Trataremos aqui apenas dos resultados referentes à $1^{\mathrm{a}}$. pessoa do plural. A autora obteve 693 dados de $1^{\mathrm{a}}$. pessoa, sendo 372 (53\%) com desinência e 321

\footnotetext{
${ }^{4}$ No Português do Brasil, ao contrário do Português Europeu, não existe "a oposição entre os timbres abertos e fechados das vogais tônicas $a$, $e$ e $o$ seguidas de uma consoante nasal: ocorre nesse caso, apenas o timbre fechado" (TEYSSIER, 1997, p.102). Portanto, não há, no modo indicativo, diferença entre a primeira pessoa do plural no presente e no pretérito perfeito, em nenhuma das três conjugações: cantamos / vendemos / partimos. Castilho (1992, p.246, item 3.2.1) também registra essa indiferenciação morfológica. Uma suposição, então, a respeito da variação na vogal temática é a de que ela sirva para regularizar o sistema, reintroduzindo a distinção entre presente e pretérito perfeito.

${ }^{5}$ Não estamos considerando, nesta análise, a variação na realização da vogal da desinência, se /o/ ou /u/. 198
} 
(47\%) sem desinência, resultados, portanto, muito semelhantes aos do estudo de Bortoni-Ricardo (1985), recém-mencionado.

Em Rodrigues (1992) dois grupos de fatores são discutidos, um lingüístico, a realização do sujeito sintático, e outro social, o sexo dos informantes. O primeiro grupo tinha como fatores pronome nós explícito, não-explícito (sujeito nulo) e sujeito não-pronominal (por exemplo, eu e meu marido, cf. p.161). Os resultados revelam que pronome não-explícito favorece a concordância $(74 \%$ de marcas e probabilidade de 0,81 ), em contraposição aos outros dois fatores, que a desfavorecem: pronome nós explícito $(47 \%$ e probabilidade de 0,45$)$ e sujeito nãopronominal $(32 \%$ e probabilidade de 0,22 ). Para Rodrigues, esse resultado tem explicação funcional: a perda informacional causada pela omissão de sujeito precisa ser compensada pela presença da DNP. Ainda que a definição dos fatores seja, nesse trabalho, distinta da análise feita por Bortoni-Ricardo (1985), chama atenção o fato de o sujeito nulo favorecer concordância nas duas investigações, com $84 \%$ ou $74 \%$ de presença de DNP-P4.

O segundo grupo de fatores discutido por Rodrigues (1992) - sexo teve os seguintes resultados: os homens usam mais a marca de concordância $(63 \%$ e prob. de 0,57). A autora atribui esse resultado ao fato de os homens, nas circunstâncias sociais estudadas, terem mais facilidade do que as mulheres de conseguir emprego, em geral em outros bairros, e terem de se adaptar aos hábitos língüísticos urbanos para não sofrerem discriminação lingüística e social: "o homem tem mais opções profissionais na cidade grande que as mulheres, ou tem mais possibilidade de acesso a atividades que lhe conferem um estatuto ocupacional e, conseqüentemente, uma identidade social" (RODRIGUES, 1992, p.169). As mulheres, no entanto, por permanecerem mais ligadas ao trabalho doméstico e ao bairro, e terem menores oportunidades profissionais, "tendem a usar as formas verbais não-padrão, sem marcas formais de concordância do verbo com seu sujeito P4" (RODRIGUES, 1992, p.168). Esses resultados são comparáveis aos de Bortoni-Ricardo (1985), indicando que o papel de homens e mulheres nos processos de variação e mudança lingüística dependem dos papéis que desempenham nas sociedades e do modo como nelas se inserem.

Naro et al. (1999) estudaram a variação na distribuição dos pronomes de primeira pessoa do plural e as mudanças no padrão de uso das flexões verbais correspondentes no português falado no Brasil, a partir de dados coletados no Rio de Janeiro. Sua amostra estava estratificada por sexo, quatro faixas etárias (6 a 12 anos, 13 a 20 anos, 21 a 40 anos e acima de 40 anos) e dois níveis de escolaridade (até três anos e de quatro a oito anos de escolaridade). Foram consideradas as seguintes variantes: a) nós falamos/fala; b) a gente fala/falamos; c) zero fala/falamos.

Para analisar a alternância entre - mos e zero, os autores investigaram um grupo de fatores chamado saliência fônica. Trata-se de uma hierarquia das formas verbais em função do maior ou menor contraste entre a forma com a desinência - 
mos e a forma de $3^{\mathrm{a}}$. pessoa do singular. Transcrevemos, a seguir, a tabela dos autores, contendo os cinco níveis previstos, exemplos e respectivas descrições.

Hierarquia de saliência fônica (cf. NARO et al., 1999, p.203)

\begin{tabular}{|l|l|l|}
\hline & Exemplo & Descrição \\
\hline 1 & falava/falávamos & A oposição -VI-Vmos não é tônica nas duas formas \\
\hline 2 & $\begin{array}{l}\text { fala/falamos } \\
\text { trouxe/trouxemos }\end{array}$ & A oposição -VI-Vmos é tônica em uma das duas formas \\
\hline 3 & $\begin{array}{l}\text { está/estamos } \\
\text { tem/temos }\end{array}$ & A oposição -VI-Vmos é tônica nas duas formas \\
\hline 4 & $\begin{array}{l}\text { comeu/comemos } \\
\text { partiu/partimos } \\
\text { vai/vamos } \\
\text { foi/fomos }\end{array}$ & $\begin{array}{l}\text { A oposição -V/-Vmos é tônica nas duas formas e a 3a. pes. sing. } \\
\text { Tem uma semivogal que não aparece na 1a. pes. pl. }\end{array}$ \\
\hline 5 & $\begin{array}{l}\text { falou/falamos } \\
\text { é/somos }\end{array}$ & $\begin{array}{l}\text { A oposição -V/-Vmos é tônica nas duas formas e a vogal } \\
\text { acentuada é diferente }\end{array}$ \\
\hline
\end{tabular}

Fig. 1

$\mathrm{Na}$ amostra estudada por Naro et al. (1999), todas as formas do nível 1 foram de imperfeito. Além disso, houve uma distribuição enviesada dos verbos nesta hierarquia, com relação ao tempo verbal. O pretérito perfeito se concentrou nos níveis 4 e 5 e o presente, nos níveis 2 e 3 . O imperfeito só pode aparecer no nível 1. Por isso, os autores estabeleceram, paralelamente, um grupo de fatores relativo a tempo verbal que permitisse opor presente e perfeito.

$\mathrm{Na}$ análise quantitativa da alternância entre - mos e zero foi necessário excluir o nível 1 da hierarquia, contendo os casos de imperfeito, pois o -mos praticamente não ocorreu neste nível $(3,8 \%)$, tanto para sujeito nós quanto para sujeito a gente. Este contexto, portanto, se mostrou altamente favorável à desinência zero. Para Naro et al., contudo, a explicação não é por esquiva da forma proparoxítona, como postula Bortoni-Ricardo, e sim por menor saliência fônica de distinção entre a $3^{\mathrm{a}}$. pessoa do singular e a $1^{\mathrm{a}}$. pessoa do plural. No presente estudo não testamos a saliência fônica, por termos pouquíssimos casos de desinência zero, como será visto adiante.

No estudo de Naro et al., nas 2.160 ocorrências de formas verbais com o sujeito nós, a desinência -mos apareceu mais nos níveis mais altos de saliência. Para os falantes mais velhos a saliência foi o único fator significativo. Já para os mais jovens, o tempo verbal também foi selecionado pelo programa estatístico, ou seja, para esses falantes, mesmo uma forma saliente terá menos chance de ocorrer com o -mos se não for um caso de pretérito perfeito. Já das 877 formas verbais com o sujeito a gente, 183 apareceram com -mos (20,9\%). Nesta análise, além da saliência fônica e do tempo verbal (que apresentaram o mesmo padrão descrito para o sujeito nós), foi selecionada também a posição do sujeito em relação ao verbo (distante ou não). Quando o sujeito a gente está próximo (antecedendo o 
verbo e dele separado por no máximo cinco sílabas), as chances de ocorrer -mos são baixas.

No dialeto rural-urbano investigado por Bortoni-Ricardo (1985, p.21112), o índice de ocorrência de $a$ gente com verbo flexionado na forma - mos foi tão baixo que a autora decidiu não incluir esses dados na análise. Nos dados de Porto Alegre do VARSUL (24 entrevistas analisadas) há apenas uma ocorrência de sujeito a gente combinado com desinência -mos, dita jocosamente pelo falante ${ }^{6}$. Inicialmente, portanto, não há evidências semelhantes às encontradas por Naro et al. (1999). Em nossos dados, por conseguinte, a gente concorda com verbo na $3^{\mathrm{a}}$. pessoa do singular, de modo que, neste estudo, consideramos só os casos de sujeito nós, nulo ou SN.

Outra referência importante para nosso estudo é o artigo de Ataliba T. de Castilho (1992) intitulado "O Português do Brasil", publicado em apêndice ao livro "Lingüística Românica", de R. Ilari. Neste artigo, Castilho (1992, p.250) afirma que, além da forma padrão - mos, a concordância de primeira pessoa do plural apresenta-se também através da perda progressiva do $-s$ para compor o morfema número-pessoal (nós cantamo), podendo ocorrer, ainda, a omissão do morfema número-pessoal -mos, caso se constitua uma palavra-alvo proparoxítona: nós tinha (por nós tínhamos). Chamou nossa atenção o fato de esse autor apresentar essas variantes como características da fala de sujeitos não-escolarizados, aspecto que pretendemos discutir neste trabalho.

Um exame preliminar das entrevistas do VARSUL, em que todos os informantes são escolarizados, tendo, no mínimo, de 4 a 5 anos de estudo, revela a presença de todas as variantes ${ }^{7}$ descritas por Castilho (1992), como se observa nos exemplos a seguir:

(4) zero: Nós era agricultor. (PAN06, linha 1.128) ${ }^{8}$

(5) -mo: Nós falamo o nosso alemão. (PAN16, linha 1.067)

(6) -mos: Nós falamos corretamente português. (POA01, linha 513)

(7) -emo no presente do indicativo: Olha, eu compro lá, né? Porque é perto, né?E nós compremo tudo lá assim, né? O que a gente compra, né? Compro sempre lá, né? (PAN06, linha 1.207)

(8) -emo no pretérito perfeito do indicativo: Aí tá, aí fomo pro restaurante, mas um restaurante lindo, dois pisos. Cheguemo no restaurante e era uma gurizada,

\footnotetext{
${ }^{6}$ A ocorrência é a seguinte: E pra se entrá numa faculdade também não é fácil, né? Então a gente 'stamos aí, né?

[POA23, 1. 238] e foi produzida por um informante do sexo masculino, de menos de 50 anos, com escolaridade de segundo grau.

${ }^{7}$ Não consideramos, nesta análise, variantes relacionadas com a realização da vogal na desinência, se /o/ ou /u/. Isso fica para consideração futura.

${ }^{8} \mathrm{~A}$ origem dos dados é identificada mediante o emprego das abreviaturas constantes no Banco VARSUL: PAN para Panambi e POA para Porto Alegre. A designação da localidade vem sempre seguida do número que identifica a entrevista de onde o dado foi extraído e da respectiva linha na transcrição.
} 
mas gurizada, gurizada mesmo, sabe o que que era? Tudo pivetezinho, mas gurizada mesmo. (POA01, linha 856).

Cumpre destacar, de antemão, que os exemplos (7) e (8) mostram, também, que a forma não-padrão quanto à vogal temática ocorre em orações no presente e no perfeito, não correspondendo, portanto, à descrição de BortoniRicardo antes mencionada.

Em vista dessas constatações, temos por objetivo verificar em que medida essa variação ocorre nas duas comunidades do RS e, com base na metodologia da sociolingüística quantitativa laboviana, investigar que fatores lingüísticos e sociais podem estar influenciando a escolha das variantes por parte dos falantes. Em especial, procura-se verificar em que medida a escolaridade está associada ao emprego das formas atestadas. Os resultados aqui apresentados retomam e aprofundam a análise efetuada em Maya, Silva e Zilles (1999).

A reflexão sobre a concordância de primeira pessoa do plural, obviamente, não pode deixar de considerar, além dos fenômenos de variação já mencionados (apagamento do /s/, omissão da desinência, alternância de vogal temática), um outro, mais geral e, provavelmente, mais intenso, relacionado com o uso de a gente em lugar de nós. Por limitações óbvias, não podemos nos ocupar disso aqui. Convém registrar, contudo, que, sob o nosso ponto de vista, a concordância de primeira pessoa do plural é indiretamente afetada pela gramaticalização de a gente, à medida que a gente substitui nós, num processo semelhante ao da substituição de $t u$ por você com a respectiva alteração do paradigma verbal, como caracteriza Faraco (1996). Apesar de não termos encontrado ocorrências de $a$ gente com verbo flexionado na DNP-P4 nos dados do Varsul, não podemos deixar de mencionar que os professores de português de Porto Alegre reportam esse uso na fala e na escrita de seus alunos das camadas populares. São observações assistemáticas, mas constantemente referidas, daí a necessidade de ampliar esta investigação, até porque esse relato vai ao encontro do que afirmam Naro et al. (1999).

Em artigo sobre inovações morfológicas no português do Brasil, Maria Cristina Figueredo Silva (1998, p.190-91) afirma que a morfologia específica de primeira pessoa do plural está em extinção. Segundo a autora, são as mudanças no sistema pronominal que acarretam a redução do sistema de desinências verbais: "Já é fato notório que o português brasileiro está em um processo de franca perda da parte da flexão verbal relativa à desinência número-pessoal, devido à renovação no quadro pronominal promovida pela entrada de você(s) e, mais recentemente, de $a$ gente" (SILVA, 1998, p.190).

Ainda que pareça perfeitamente plausível e historicamente demonstrável que essas mudanças no sistema pronominal afetam a concordância verbal (cf. FARACO, 1996), este é apenas um dos percursos da língua portuguesa no Brasil, o de um sistema que tinha/tem concordância e que perde marcas com as alterações do sistema pronominal. Há, no entanto, que se reconhecer a existência de um outro 
percurso da língua no país, resultante de sua aquisição por falantes de outras línguas, processo que se repetiu (e se repete ainda) inúmeras vezes ao longo da história, desde a chegada dos portugueses em 1.500. Neste outro percurso, estabeleceu-se, grosso modo, na zona rural, de São Paulo até o Nordeste, variedades dialetais com apenas uma diferenciação número-pessoal no verbo, a de primeira pessoa do singular. A primeira marca pessoal a ser aprendida nas situações de contato, segundo Emmerich (1984), enquanto todas as outras pessoas são não-marcadas. Neste percurso, os falantes da zona rural se engajaram em intensos processos migratórios na Segunda metade do século XX, ora mudando de região, ora, e principalmente, mudando do campo para a cidade ${ }^{9}$, onde vieram a constituir as variedades populares. Nestas, não parece adequada a descrição de perda de concordância, pois não se pode perder o que não se tem. Nestas variedades populares, conforme Guy (1981), Bortoni-Ricardo (1985) e Rodrigues (1992), os falantes estão adquirindo as desinências número-pessoais que encontram na fala urbana e estão, simultaneamente, aprendendo na escola as desinências da língua padrão. Assim, estamos diante de processos cuja direção é oposta, mas cujo resultado pode vir a ser convergente! Por isso, julgamos prematura qualquer previsão final.

O presente estudo se propõe a discutir em que medida se pode falar em extinção da desinência de primeira pessoa do plural considerando os dados de língua falada de duas comunidades do Rio Grande do Sul. Vale mesmo perguntar o que significa estar em extinção e como essa previsão se coaduna com os dois percursos de mudança antes referidos. Voltaremos a essa questão ao discutirmos nossos resultados.

\section{HIPÓTESES E QUESTÕES}

Com base na revisão da literatura, parece adequado supor que haja dois processos determinando o uso de formas não-padrão: um fonológico, de apagamento do /s/, e outro, morfossintático, de variação na aplicação da regra de concordância verbal. Diversos estudos atestam a existência de regra de apagamento do /s/, entre eles, Guy (1981) e Scherre $(1996)^{10}$, assim como demonstram amplamente a variabilidade na realização da concordância, seja verbal, seja nominal, no português do Brasil.

Também com base na literatura, é razoável supor que maior escolaridade favoreça mais o uso da forma padrão -mos. Por outro lado, na comparação entre as

\footnotetext{
${ }^{9}$ Dados do IBGE mostram que, 1940, a população urbana no Brasil era de 12.880 .182 (31\%) e a rural era de $28.356 .133(69 \%)$, com um total de 41.236 .315 . Em 1996, a população urbana no Brasil era de 123.076.831 (78,4\%), enquanto a rural era de 33.993 .332 (21,6\%), com um total de 157.070.163. (Fonte: Diário Catarinense, 27/07/2000, p. 4.)

${ }^{10}$ Estão sendo referidos os artigos sobre concordância nominal na obra organizada por Oliveira e Silva \& Scherre, 1996.
} 
comunidades de Porto Alegre e Panambi, levantamos a possibilidade de interferência em virtude do contato entre alemão e português nesta última.

As hipóteses testadas nesta análise são as seguintes:

a) a forma verbal proparoxítona favorece a omissão da desinência número pessoal -mos;

b) as formas não-padrão (zero e -mo) são favorecidas na fala dos informantes com menor grau de escolaridade;

c) as formas não-padrão são mais favorecidas em Panambi, em decorrência de aquisição tardia do português pelos falantes bilíngües desta comunidade;

Além dessas hipóteses, este trabalho explora as questões a seguir. Em que medida a DNP-P4 é uma forma em extinção, considerando dados de língua falada no Rio Grande do Sul? Qual o papel da posição do sujeito em relação ao verbo para a realização da concordância? Interessa tanto a ordem sintática quanto o caráter adjacente ou não? $\mathrm{O}$ contexto seguinte desempenha algum papel no apagamento do /s/ na DNP-P4? Há associação sistemática entre a mudança de vogal temática e a forma -mo? E entre a vogal temática /e/ não padrão e o tempo verbal?

\section{METODOLOGIA}

A análise aqui empreendida ampara-se na teoria sociolingüística laboviana, no sentido de investigar relações entre a estrutura lingüística e a estrutura social.

\section{Amostra}

Os dados analisados foram obtidos de entrevistas do Banco de Dados VARSUL. Nesta etapa, a amostra compreende 32 entrevistas sociolingüísticas gravadas em áudio e transcritas segundo o sistema adotado no VARSUL. O armazenamento computacional, também proporcionado pelo projeto, foi feito pelo programa Editor (ENGESIS).

\section{Análise}

Uma vez selecionadas as entrevistas, foi feita a busca automática das ocorrências, mediante o programa Interpretador (ENGESIS) e a leitura das entrevistas. Identificadas as ocorrências, elas foram digitadas e codificadas em relação às variáveis analisadas, usando-se o programa QUICK EDITOR. A análise estatística foi feita com o programa estatístico VARBRUL (PINTZUK, 1988), em três etapas:

a) na primeira etapa, investigou-se a distribuição das três variantes, mediante uma rodada em que a variável dependente era ternária; 
b) na segunda, considerou-se a omissão da desinência (zero) versus -mo e - mos reunidos (rodada com variável dependente binária);

c) por fim, na última rodada, examinou-se a alternância das formas $-m o$ e $-m o s$, excluindo os casos de omissão da desinência (rodada binária).

Esse procedimento foi adotado para permitir testar se há duas regras variáveis em atuação, a primeira, relacionada com a presença/ausência da DNP-P4, e a outra, relacionada com o apagamento do /s/ na desinência -mos.

\section{Variáveis}

A variável em estudo ficou definida como desinência número-pessoal com primeira pessoa do plural (DNP-P4), abarcando as seguintes variantes: DNP-P4 padrão -mos; DNP-P4 não-padrão com apagamento do /s/, correpondendo à realização -mo; e DNP-P4 não-padrão, realizada como zero — esta última será referida, de agora em diante, como desinência zero.

Foram investigadas 13 variáveis ou grupos de fatores, 9 lingüísticos e 4 sociais, conforme especificamos a seguir.

As variáveis lingüísticas foram as seguintes:

1) conjugação do verbo - primeira, segunda ou terceira conjugação;

2) tempo e modo verbal - considerando formas do indicativo, subjuntivo, imperativo, infinitivo e perífrase (ir + infinitivo);

3) realização do sujeito - pronome nós explícito, nulo ou sintagma nominal;

4) estrutura verbal - simples ou composta;

5) tipo de discurso - reportado ou não-reportado;

6) contexto seguinte - vogais, consoantes e pausa;

7) posição do sujeito em relação ao verbo - posposição, anteposição direta, distância entre sujeito e verbo de uma a três sílabas e distância entre sujeito e verbo de mais de três sílabas;

8) alternância de vogal temática (apenas para formas do presente e pretérito perfeito do indicativo de primeira conjugação) $-e$ (cantemos) e $a$ (cantamos);

9) posição do acento na forma verbal alvo - proparoxítonas ou paroxítonas.

As variáveis sociais foram as seguintes:

1) escolaridade - primário ou segundo grau;

2) sexo - feminino ou masculino;

3) idade - mais de 50 anos ou menos de 50 anos;

4) comunidade - Panambi ou Porto Alegre.

\section{RESULTADOS}

Na Fig.2 apresentamos a distribuição percentual das três variantes consideradas: desinência zero, desinência padrão - mos e desinência não-padrão mo. 


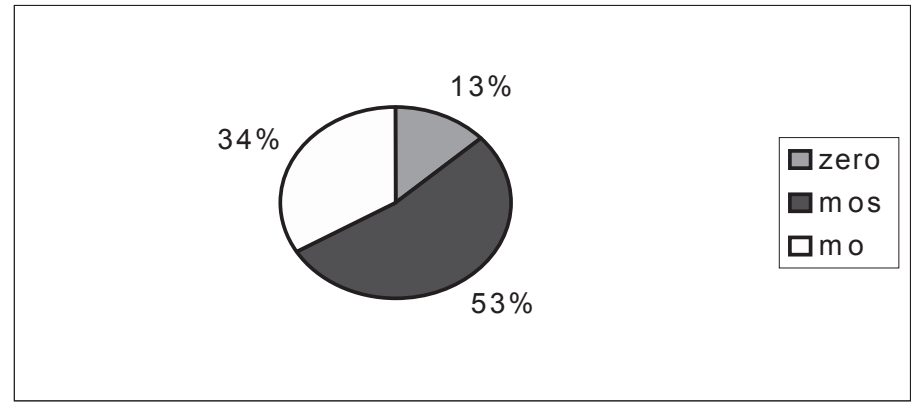

Fig.2

Lembremos a afirmação de Silva (1998, p.191) antes citada, de que a morfologia específica de primeira pessoa do plural estaria em extinção. À primeira vista, nossos resultados não parecem sustentar essa afirmação. As ocorrências com DNP-P4, seja a padrão, seja a com o apagamento do /s/, predominam em relação a zero nesta amostra. O número total de ocorrências foi 1.035 , sendo $579(53 \%)$ de forma padrão (-mos), 347 (34\%) de apagamento do /s/ (-mo), contra apenas 109 $(13 \%)$ casos de desinência zero. Decorre daí que o emprego da desinência (somando-se os casos de $-m o s$ e $-m o$ ) chega a $87 \%$, um índice muito robusto de aplicação de regra, muito mais alto, por exemplo, que o encontrado por BortoniRicardo (56\%) ou por Rodrigues (53\%), devido, possivelmente, a diferenças na composição social das amostras.

Assim, se a afirmação de Silva se justifica, aqui no Rio Grande do Sul a mudança estaria em fase inicial. No entanto, sabemos bem que outros fatores concorrem para essa possível extinção, sendo sobremaneira importante o crescente uso de a gente em lugar de nós. Ora, se o uso de a gente, numa análise parcial de 12 entrevistas de Porto Alegre, chega a $80 \%$ das referências à $1^{\text {a }}$. pessoa do plural ${ }^{11}$ (incluindo a referência genérica), sempre com o verbo na terceira pessoa do singular, então sim podemos pensar em progressiva redução de uso e, quem sabe, futura extinção.

Uma questão, contudo, merece ser considerada: as formas lingüísticas, em sociedades letradas (mesmo nas que têm alto índice de analfabetismo, como o Brasil), parecem custar muito a efetivamente desaparecer da língua como um todo, ou do conjunto de variedades que constitui a língua de uma comunidade. Um exemplo óbvio disso é o caso do pronome "vós", quase totalmente substituído pelo

${ }^{11}$ Este percentual deve ser visto com cautela, uma vez que se refere à análise de apenas 425 casos. Estamos investigando essa alternância nos dados do VARSUL, de modo que, futuramente, será possível discutir essa questão de modo mais apropriado. 
pronome "vocês" na maioria dos contextos, exceto na oratória extremamente formal e em textos religiosos. Em Portugal, a resistência é ainda maior, com a permanência do possessivo "vosso/a". Por isso, a afirmação sobre a extinção da desinência-mos parece precipitada.

Pensamos que a variação entre nós e a gente poderá levar a uma redução drástica do uso da DNP-P4 (-mos, -mo), mas seu desaparecimento poderá ser retardado ou até bloqueado, já que, na escrita, especialmente na escrita formal, ainda se impõe exclusivamente o uso de nós e, na escola, haja, clara ou veladamente, o cerceamento do uso de a gente na redação ou na produção textual dos alunos. Além disso, mesmo observando de forma assistemática a literatura ficcional atual, verifica-se que a forma nós parece preferida em contextos narrativos, enquanto a forma a gente só surge nos diálogos. No jornalismo escrito, são as matérias que representam a fala (entrevistas), os quadrinhos e os textos informais que apresentam a gente. De resto, prevalece o emprego de nós, salvo melhor análise. Desse modo, talvez sobrevenha não a extinção, e sim a convivência das duas formas pronominais com especialização pragmática de funções.

\section{A omissão da desinência}

Examinemos mais de perto a omissão versus a realização da desinência, com os resultados da Segunda etapa da análise estatística. As variáveis selecionadas como significativas pelo programa VARBRUL, em relação à omissão da desinência (zero), foram, nesta ordem, sílaba tônica, escolaridade, posição do sujeito em relação ao verbo e comunidade. Discutimos primeiro os resultados das variáveis lingüísticas e, a seguir, o das sociais.

Quanto à sílaba tônica, conforme a Fig.3, os resultados mostram que uma forma verbal alvo proparoxítona favorece muitíssimo a omissão da desinência, com peso de 0,97 , contrastando com o que ocorre quando a forma verbal alvo é palavra paroxítona, em que o peso cai para 0,28 (apenas 2\%), desfavorecendo a desinência zero. Isso significa que, na amostra considerada, praticamente não há ocorrências como nós canta, razão por que não é possível explorar, nesta análise, a variável de saliência fônica proposta por Naro et al. (1999).

Omissão da desinência verbal com P4 (N, \% e peso) em relação à variável sílaba tônica; dados de POA e PAN (VARSUL)

\begin{tabular}{|l|l|l|l|}
\hline Fatores & Zero N & $\%$ & Peso \\
\hline Proparoxítona & $94 / 221$ & 43 & 0,97 \\
\hline Paroxítona & $15 / 814$ & 2 & 0,28 \\
\hline
\end{tabular}

Fig.3

O resultado do grupo de fatores sílaba tônica é favorável a nossa hipótese (a), de que palavras proparoxítonas favorecem a omissão de -mos. Os falantes parecem evitar as proparoxítonas, seguindo a tendência geral da língua de ter 
palavras predominantemente paroxítonas: a omissão da desinência corta a última sílaba da palavra proparoxítona, resultando uma forma paroxítona. Esse resultado é compatível com o de Bortoni-Ricardo (1985, p.212), ainda que as taxas de desinência zero sejam muito distintas: $90 \%$ naquele estudo, em comparação com apenas $43 \%$ neste.

Por outro lado, é necessário registrar ainda que os poucos casos de zero em contextos nos quais a forma verbal alvo seria palavra paroxítona envolvem, nas duas comunidades, contextos complexos como o de emprego de infinitivo (no padrão seria flexionado) ou de futuro do subjuntivo. Há, também, casos de sujeito posposto ao verbo, como se observa nos excertos abaixo.

(9) zero em contexto do futuro do subjuntivo:

- Se nós dois ficá sentado aqui na área tomando chimarrão, vão dizer: "Dois vagabundos, né?" (PAN20, linha 1.043);

(10) zero em contexto de infinitivo flexionado:

- Então muitas vezes nós cansava de jogar um com o outro em apostas pra nós $\operatorname{subi}(r)$ as escadas de joelhos, quem chegasse primeiro, né? (POA01, linha 222);

(11) zero em contexto de ordem Verbo-Sujeito;

- Fica só nós (POA03, linha 945);

- Saiu eu e a minha esposa (POA11, linha 704).

Quanto à variável posição do sujeito em relação ao verbo, os resultados apresentados na Fig.4 mostram que a posposição, com peso de 1,00, e a distância de mais de 3 sílabas, com peso de 0,62, são os fatores que favorecem a desinência zero; a distância de uma a três sílabas tem peso de 0,52 , e a anteposição direta tem peso de 0,48 , ambos muito próximos do ponto neutro $(0,50)$. É necessário esclarecer que não foram computados aqui os casos de sujeito nulo $(\mathrm{N}=460)$, dos quais apenas $4 \%(\mathrm{~N}=19)$ correspondiam a desinência zero.

Omissão da desinência verbal com P4 (N, \% e peso) em relação à variável posição do sujeito; dados de POA e PAN (VARSUL)

\begin{tabular}{|l|l|l|l|}
\hline Fatores & Zero N & $\%$ & Peso \\
\hline Posposição & $4 / 5$ & 80 & 1,00 \\
\hline Mais de 3 sílabas & $2 / 23$ & 9 & 0,62 \\
\hline Anteposição direta & $77 / 458$ & 17 & 0,48 \\
\hline 1 a 3 sílabas & $9 / 93$ & 10 & 0,52 \\
\hline
\end{tabular}

Fig.4

Tende a haver mais marca de concordância entre o verbo e o termo que lhe é adjacente à esquerda. À medida que aumenta a distância entre o verbo e o sujeito, há mais probabilidade de ocorrer desinência zero, contrariando, portanto, uma explicação funcional segundo a qual a adjacência entre sujeito e verbo é que favoreceria a omissão da desinência, por maior facilidade de processamento. Com a posposição do sujeito, a omissão da desinência é quase categórica: são 4 de 5 
ocorrências, com peso de 1,00. Apesar de o número de ocorrências ser muito baixo, esse resultado vai na mesma direção dos resultados de muitos outros trabalhos, quanto à grande redução da concordância com posposição do sujeito ao verbo. Essa tendência aparece mesmo na escrita, como registrou Mattoso Camara Jr. (1972), no artigo anteriormente citado. Na língua falada, observe-se, por exemplo, os resultados de Guy (1981) e Lira (1986), entre tantos outros.

De modo geral, portanto, os contextos que favorecem a omissão da desinência nesta amostra são forma verbal alvo proparoxítona e sujeito posposto ou distante do verbo. Passemos, então, à análise dos resultados de escolaridade e comunidade.

Com relação à escolaridade, constata-se que são os falantes com primário que favorecem a desinência zero, com peso de 0,74 , ao passo que os falantes com segundo grau a desfavorecem fortemente, com peso de 0,25 .

Omissão da desinência verbal com P4 (N, \% e peso) em relação à variável escolaridade; dados de POA e PAN (VARSUL)

\begin{tabular}{|l|l|l|l|}
\hline Fatores & Zero N & $\%$ & Peso \\
\hline Primário & $86 / 530$ & 16 & 0,74 \\
\hline 20 grau & $23 / 505$ & 5 & 0,25 \\
\hline
\end{tabular}

Fig.5

O peso relativo alto de 0,74 para a desinência zero no caso de falantes de baixa escolaridade já era esperado. Entretanto, o peso de 0,25 para os informantes com segundo grau, apesar de revelar desfavorecimento, mostra que o fenômeno não se restringe aos não- ou menos escolarizados, sendo, portanto, mais amplo do que afirma Castilho (1992). Esses resultados, então, sustentam nossa hipótese (b).

Por fim, com relação à comunidade, é Panambi que favorece a omissão da desinência, com peso de 0,57 , ao passo que Porto Alegre a desfavorece, com peso de 0,41 , resultado compatível com nossa hipótese (c).

Omissão da desinência verbal com P4 (N, \% e peso) em relação à variável localidade; dados de POA e PAN (VARSUL)

\begin{tabular}{|l|l|l|l|}
\hline Fatores & Zero N & $\%$ & Peso \\
\hline Panambi & $64 / 586$ & 11 & 0,57 \\
\hline Porto Alegre & $45 / 467$ & 10 & 0,41 \\
\hline
\end{tabular}

Diante desse resultado, pode-se supor alguma influência do contato de línguas (bilingüismo alemão-português) na omissão da desinência. Isso poderia estar relacionado com a aquisição tardia do português, geralmente na escola, nessas comunidades bilíngües, implicando menor controle da concordância padrão ou, talvez, da regra variável de concordância. Entretanto, devemos registrar que, rodando separadamente os dados de Porto Alegre e Panambi, há somente duas variáveis em comum que o programa VARBRUL seleciona como estatisticamente 
significativas em ambas as comunidades: sílaba tônica e escolaridade. Em todas as rodadas que fizemos, esses dois grupos de fatores sempre foram selecionados em primeiro lugar como favoráveis à omissão da desinência -mos. Em Porto Alegre, também são significativos os grupos sujeito nulo versus preenchido e posição do sujeito, o que não acontece em Panambi. Não podemos nos estender nessa discussão aqui, por isso apenas registramos a diferença.

Concluímos esta parte da análise observando que a variável tempo verbal não foi selecionada como estatisticamente significativa na alternância entre zero e -mos/-mo, contrapondo nossos resultados, em princípio, aos de Naro et al. (1999). Mesmo assim, é importante ressaltar a necessidade de testar a hierarquia de saliência fônica, uma vez que nossos resultados mostraram que a desinência zero é favorecida justamente nos casos que se enquadram no nível 1 daquela análise. Se há, aqui, uma mudança em curso, ela parece estar em fase inicial, ou a escolaridade de nossos sujeitos (todos com 4 ou mais anos de estudo) está contribuindo para conter a mudança, ao menos no contexto da entrevista. Também é preciso destacar que, de acordo com a Fig.3, todos os demais casos de desinência zero alcançam apenas um índice de $2 \%$ nas palavras paroxítonas, sendo pouco provável que haja uma distribuição conforme a escala prevista por Naro et al. Se lembrarmos que são casos de ordem VS e de construções com verbos no futuro do subjuntivo e no infinitivo flexionado, de uso bem mais raro, veremos que há pouco espaço, no presente conjunto de dados, para testar a escala de saliência fônica.

\section{O apagamento do /s/ na DNP-P4}

$\mathrm{Na}$ terceira etapa da análise estatística, contrastamos o uso de -mo versus a forma padrão, tendo-se um total de 926 ocorrências assim distribuídas: 579 casos $(63 \%)$ de $-m o s$ e 347 casos $(37 \%)$ de $-m o .{ }^{12}$ As variáveis selecionadas como significativas para o apagamento do /s/ foram, nesta ordem, tempo verbal, escolaridade, vogal temática, idade, tipo de discurso, sexo e conjugação. Apresentamos, inicialmente, os resultados das variáveis lingüísticas e, a seguir, os das sociais.

Quanto ao grupo de fatores tempo verbal, conforme a Fig.7, observamos que favorecem o apagamento a perífrase ir + infinitivo, com peso de 0,81 , o presente, com peso de 0,57 , e o perfeito, com peso de 0,55 . O imperativo, com peso de 0,41 , o futuro do subjuntivo amalgamado com o infinitivo flexionado, com peso de 0,24 , e o imperfeito, com peso de 0,09 , desfavorecem a forma $-m o$.

12 Para uma discussão do processo mais amplo de apagamento do /s/ nos dados do VARSUL, remetemos o leitor para o artigo intitulado "A identidade lingüistica da comunidade de fala: paralelismo interdialetal nos padrões de variação lingüística", de Gregory Guy, neste mesmo volume. Segundo este autor, talvez seja possível postular duas entradas lexicais para o sufixo-mos, uma com e outra sem o$s$ final. Para Guy, a taxa mais elevada de ausência do $-s$ nessas palavras, em comparação com outras categorias de palavras, é resultado de seleção variável da forma -mo desse sufixo.

210 
Apagamento do /s/ na DNP-P4 (N, \% e peso) em relação à variável tempo verbal; dados de POA e PAN (VARSUL)

\begin{tabular}{|l|l|l|l|}
\hline Fatores & $-\mathrm{mo} \mathrm{N}$ & $\%$ & Peso \\
\hline Vamos + inf. & $78 / 107$ & 73 & 0,81 \\
\hline Presente & $136 / 357$ & 38 & 0,57 \\
\hline Perfeito & $113 / 280$ & 40 & 0,55 \\
\hline Imperativo & $15 / 41$ & 37 & 0,41 \\
\hline Fut subj + inf flex & $1 / 8$ & 13 & 0,24 \\
\hline Imperfeito & $4 / 125$ & 3 & 0,09 \\
\hline \multicolumn{4}{|l}{} \\
\hline
\end{tabular}

Os resultados referentes a este grupo de fatores parecem indicar que os tempos/modos verbais de uso mais raro na língua falada - como o subjuntivo e o infinitivo flexionado - favorecem a forma padrão -mos. Já os tempos verbais presente e pretérito perfeito, bem como a perífrase vamos + infinitivo, que são mais freqüentes na fala, favorecem o apagamento do $/ \mathrm{s} /$. O imperfeito desfavorece muitíssimo a forma -mo (apenas 3\% dos casos), pois, como já discutimos na seção anterior, há um outro processo associado a esse tempo verbal (a formação de proparoxítona é evitada pela omissão da desinência inteira). Esse resultado pode ser interpretado como revelador de uma forte restrição à realização de formas como cantávamo, escrevíamo e partíamo $^{13}$ e impõe a necessidade de futuras investigações que contemplem a correlação entre regras morfossintáticas e fonológicas.

Uma observação, porém, precisa ser acrescentada. A perífrase vamos + infinitivo, o tempo presente e o modo imperativo podem estar sendo influenciados pelo alto índice de ocorrência de vamos, forma do verbo ir comum aos três fatores. Por isso, resolvemos avaliar essa questão mais de perto. De fato, verificamos que, do total de 347 casos de apagamento do /s/, 114 são de vamo, o que corresponde a $32,8 \%$. Desses 114, aproximadamente $70 \%(\mathrm{~N}=78)$ são de perífrase vamos + infinitivo. Supomos que essa tendência de haver muito mais apagamento do /s/ nesses casos possa estar vinculada ao processo de gramaticalização ${ }^{14}$ do verbo $i r$ como auxiliar. A testagem disso dependeria de um estudo mais completo do apagamento do /s/ em final de palavra, o que escapa aos propósitos deste trabalho.

Quanto à alternância de vogal temática, os resultados estão na Fig.8. Lembramos que neste caso só foram incluídos os dados de presente e pretérito perfeito do indicativo e que esta não é considerada uma variável explicativa para o

\footnotetext{
${ }^{13}$ Como resultado de uma observação assistemática, podemos dizer que os falantes nativos de português de Porto Alegre tendem a considerar que essas formas não são possíveis ou não ocorrem. Seria útil, neste caso, um teste de julgamento de aceitabilidade. Note-se que essa restrição, melhor caracterizada, talvez, como monitoramento, estaria bloqueando a aplicação de uma regra fonológica de apagamento do $/ \mathrm{s} /$.

${ }^{14}$ Uma das características dos processos de gramaticalização é justamente a redução formal ou perda de material fônico, cf. Castilho (1997, p.32)
} 
apagamento do /s/. Pretendíamos apenas testar a associação entre os dois fenômenos.

Apagamento do /s/ na DNP-P4 (N, \% e peso) em relação à variável vogal temática; dados de POA e PAN (VARSUL)

\begin{tabular}{|l|l|l|l|}
\hline Fatores & $(-\mathrm{mo}) \mathrm{N}$ & $\%$ & Peso \\
\hline le/ & $42 / 44$ & 95 & 0,93 \\
\hline lal & $56 / 220$ & 25 & 0,37 \\
\hline \multicolumn{2}{|l|}{ Fig.8 }
\end{tabular}

Como se observa na Fig.8, a substituição da vogal temática /a/ por /e/ está fortemente associada ao apagamento de $/ \mathrm{s} /$, com peso de 0,93 ( $95 \%$ dos casos), um resultado muito alto. Já o emprego da vogal temática /a/, própria da língua padrão, se associa muito menos com o apagamento do $/ \mathrm{s} /$ : apenas $25 \%$ dos casos, com peso de 0,37 .

Um detalhamento se faz necessário aqui, sobre o cruzamento de vogal temática e tempo verbal. Registramos a seguinte distribuição das ocorrências de vogal temática /e/ em lugar de /a/, andemo em lugar de andamo(s): 22 ocorrências no Presente do Indicativo ( 20 com desinência -mo e 2 com desinência padrão) e 22 ocorrências no Pretérito Perfeito, todas com a desinência -mo. Assim, nossos dados, de fato, não sustentam a relação que vem sendo feita na literatura entre o uso de vogal /e/ em lugar de vogal/a/ e o tempo verbal Pretérito Perfeito.

Outro grupo de fatores selecionado pelo VARBRUL foi tipo de discurso. Os resultados estão na Fig.9. Na amostra aqui considerada, o discurso reportado direto favorece fortemente a variante - $m o$, com peso de 0,69 , em comparação com o discurso não-reportado.

Apagamento do /s/ na DNP-P4 (N, \% e peso) em relação à variável tipo de discurso; dados de POA e PAN (VARSUL)

\begin{tabular}{|l|l|l|l|}
\hline Fatores & $(-\mathrm{mo}) \mathrm{N}$ & $\%$ & Peso \\
\hline Reportado direto & $57 / 76$ & 75 & 0,69 \\
\hline Não reportado & $290 / 850$ & 34 & 0,48 \\
\hline
\end{tabular}

A tendência de apagar o /s/ da DNP-P4 no discurso reportado direto precisa ser melhor investigada. Qual o tipo de discurso que está sendo reportado: formal ou informal? Trata-se de interação (reportada) simétrica ou assimétrica? Qual é a função do trecho reportado no discurso em que se insere? Essa é, pois, uma questão que fica em aberto por ora.

$\mathrm{O}$ último grupo de fatores lingüísticos a ser discutido (e o último selecionado pelo VARBRUL nesta rodada) foi a conjugação verbal. De acordo com a Fig.10, a terceira conjugação favorece o apagamento do /s/ na DNP-P4, com peso de 0,60 ; ao contrário, a primeira conjugação, com peso de 0,46 , e a segunda, com peso de 0,44 , o desfavorecem. 
Apagamento do /s/ na DNP-P4 (N, \% e peso) em relação à variável conjugação; dados de POA e PAN (VARSUL)

\begin{tabular}{|l|l|l|l|}
\hline Fatores & $(-\mathrm{mo}) \mathrm{N}$ & $\%$ & Peso \\
\hline 3a Conjugação & $158 / 280$ & 56 & 0,60 \\
\hline 1a Conjugação & $105 / 332$ & 32 & 0,46 \\
\hline 2a Conjugação & $84 / 314$ & 27 & 0,44 \\
\hline
\end{tabular}

Fig.10

O peso relativo alto, de 0,60 , para a terceira conjugação ( 280 ocorrências) possivelmente está sendo influenciado pela grande incidência do verbo ir (são 134/280 ocorrências deste verbo, das quais 114 são casos de vamo). Por isso, uma medida a ser tomada é retirar da análise os dados do verbo ir a fim de verificar se esse grupo de fatores ainda será estatisticamente significativo e se essa conjugação ainda terá algum efeito sobre a realização de $-m o$.

Tratamos a seguir das variáveis sociais. Os resultados de escolaridade, apresentados na Fig.11, mostram que os falantes com primário favorecem muito o apagamento do $/ \mathrm{s} /$, com peso de 0,72 , em contraste com os de segundo grau, que o desfavorecem em grande medida, com peso de apenas 0,29. Mais uma vez, portanto, constatamos que o fenômeno é mais amplo do que afirma Castilho (1992), já que ocorre com pessoas escolarizadas, mesmo que se concentre na fala daqueles que têm poucos anos de escolaridade.

Apagamento do /s/ na DNP-P4 (N, \% e peso) em relação à variável escolaridade; dados de POA e PAN (VARSUL)

\begin{tabular}{|l|l|l|l|}
\hline Fatores & $(-\mathrm{mo}) \mathrm{N}$ & $\%$ & Peso \\
\hline Primário & $247 / 444$ & 56 & 0,72 \\
\hline $2^{\circ}$ grau & $100 / 482$ & 21 & 0,29 \\
\hline \multicolumn{2}{|l}{ Fig. 11} \\
\hline
\end{tabular}

Esses resultados relativos à escolaridade sustentam nossa hipótese (b), de que os informantes com primário apresentariam maior incidência da forma nãopadrão -mo. Se lembrarmos que esse grupo também foi selecionado na rodada anterior, referente à desinência zero, parece que temos evidências fortes para sustentar a hipótese relativa ao papel da escolaridade. Cabe, pois, perguntar: Isso indica que o controle e a produtividade da regra de concordância padrão dependem de maior escolarização? Nesse sentido, não fazem parte da competência da criança resultante da aquisição da linguagem? Para responder a essas questões, seria necessário, antes de mais nada, ampliar a amostra ora considerada e investigar também dados de aquisição. Fica, pois, a sugestão.

Quanto ao grupo de fatores idade, os resultados estão na Fig.12. Os falantes com menos de 50 anos são os que mais favorecem o apagamento do /s/ na DNP-P4, com peso de 0,63 , ao passo que os com mais de 50 anos o desfavorecem, com peso de 0,37 . 
Apagamento do /s/ na DNP-P4 (N, \% e peso) em relação à variável idade; dados de POA e PAN (VARSUL)

\begin{tabular}{|c|c|c|c|}
\hline Fatores & $(-\mathrm{mo}) \mathrm{N}$ & $\%$ & Peso \\
\hline - de 50 & $223 / 467$ & 48 & 0,63 \\
\hline + de 50 & $124 / 459$ & 27 & 0,37 \\
\hline \multicolumn{4}{|l}{ Fig.12 }
\end{tabular}

Os resultados referentes à idade sugerem resistência dos mais velhos às formas novas da língua. Os pesos relativos parecem apontar para uma mudança em curso, provavelmente, um processo mais amplo de apagamento do $/ \mathrm{s} / \mathrm{em}$ final de palavra, a exemplo do que se observa em contextos como o da segunda pessoa do singular dos verbos, ou o da concordância nominal variável. A investigação, contudo, precisa ser ampliada para incorporar informações históricas, sem as quais não parece possível afirmar a existência de processos de mudança.

Quanto ao grupo de fatores sexo, os resultados estão na Fig.13. Os falantes do sexo feminino favorecem a desinência $-m o$, com peso de 0,59 , ao passo que os falantes do sexo masculino em certa medida a desfavorecem, com peso de 0,44 .

Apagamento do /s/ na DNP-P4 (N, \% e peso) em relação à variável sexo; dados de POA e PAN (VARSUL)

\begin{tabular}{|c|c|c|c|}
\hline Fatores & $(-\mathrm{mo}) \mathrm{N}$ & $\%$ & Peso \\
\hline Feminino & $139 / 354$ & 39 & 0,59 \\
\hline Masculino & $208 / 572$ & 36 & 0,44 \\
\hline \multicolumn{4}{|c}{ Fig.13 }
\end{tabular}

Esses resultados da variável sexo também parecem apontar para uma mudança em curso, uma vez que foram as mulheres que apresentaram um peso relativo favorável ao apagamento do /s/. Essa interpretação preliminar baseia-se em Labov (1990). Conforme este autor, as mulheres lideram os processos de mudança, usando mais do que os homens as formas inovadoras. No entanto, sob uma outra ótica, ligada aos papéis e oportunidades sociais, esses resultados poderiam ser considerados comparáveis aos de Bortoni-Ricardo (1985) e Rodrigues (1992): os homens, mais do que as mulheres, empregam a desinência padrão. Mas é preciso cautela: como as duas autoras não trataram do contraste -mos versus -mo nos textos considerados, nada se pode concluir em relação a isso.

\section{Papel da escolaridade na comparação das três variantes}

Ainda que nos pareça mais adequado considerar a existência de duas regras variáveis distintas (uma relacionada com a esquiva de palavras proparoxítonas e a outra, de apagamento do /s/ em final de palavra), julgamos importante destacar o papel da escolaridade quando as três variantes são confrontadas na rodada ternária. Esse destaque se deve ao fato de ter sido este o único grupo de fatores que, nesta rodada, mostrou resultados interessantes, com 
pesos polarizados, ao contrário do que verificamos com os outros grupos, cujos pesos não apresentavam diferenças sensíveis.

No confronto das três variantes, duas tendências se explicitam: os falantes do nível primário são os que mais favorecem a desinência zero (peso de 0,50 ) e os que mais desfavorecem a forma padrão (peso de apenas 0,13 ). Os falantes de $2^{\circ}$ grau revelam tendência oposta: favorecem o emprego da forma padrão (peso de 0,61 ) e desfavorecem a desinência zero (peso de 0,17 ). Quanto ao apagamento do $/ \mathrm{s} /$, os resultados ficam em níveis intermediários para os dois grupos de falantes, ainda que o peso seja mais alto $(0,38$ contra 0,22$)$ para os falantes do primário, como se observa na Fig.14. Mais uma vez, portanto, apresentamos evidências que sustentam a hipótese (b) deste trabalho.

Distribuição (N, \% e peso) das três variantes (zero, desinência -mo e forma padrão) em relação à escolaridade na fala de Porto Alegre e Panambi (VARSUL)

\begin{tabular}{|l|l|l|l|l|l|l|l|l|l|l|}
\hline & $\begin{array}{l}\text { Formas } \\
\text { Zero } \\
\mathrm{N}\end{array}$ & $\%$ & $\begin{array}{l}\text { Não } \\
\text { Peso }\end{array}$ & $\begin{array}{l}\text { - padrão } \\
-\mathrm{mo} \\
\mathrm{N}\end{array}$ & $\%$ & Peso & $\begin{array}{l}\text { Forma } \\
- \text { mos } \\
\mathrm{N}\end{array}$ & $\%$ & $\begin{array}{l}\text { Padrão } \\
\text { Peso }\end{array}$ \\
\hline & & & & & & & & & & \\
\hline Primário & $86 / 530$ & 16 & 0,50 & $247 / 530$ & 47 & 0,38 & & $197 / 530$ & 37 & 0,13 \\
\hline $2^{\circ}$ grau & $23 / 505$ & 5 & 0,17 & $100 / 505$ & 20 & 0,22 & $386 / 505$ & 76 & 0,61 \\
\hline
\end{tabular}

$\mathrm{Na}$ análise de Ataliba de Castillo (1992, p.250) já referida, a variação da concordância verbal com P4 é considerada característica da fala de sujeitos nãoescolarizados. Nossos resultados apontaram que, de fato, pessoas menos escolarizadas são as que mais usam as formas não-padrão. No entanto, essas formas não-padrão também ocorrem na fala de pessoas escolarizadas (segundo grau), mesmo em estilo semi-distenso como é o da entrevista, embora fique evidente que tais falantes prefiram a forma padrão. A Fig.15 permite visualizar claramente as tendências relativas aos dois níveis de escolaridade.

Distribuição (peso) das três variantes (zero, desinência -mo e forma padrão) em relação à escolaridade na fala de Porto Alegre e Panambi (VARSUL)

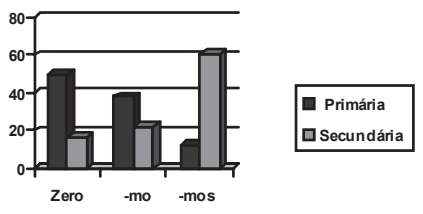

Fig. 15 
De modo geral, pode-se supor que, não fosse a escola preservar a forma padrão de concordância com - mos, o emprego das formas não-padrão poderia ser ainda mais acentuado. Esse resultado, por si só, não pode ser tomado como evidência indireta para a suposição de que a DNP-P4 seja uma forma em extinção na língua falada, pois uma das formas que estamos considerando não-padrão, a variante $-m o$, contém claramente a marca da desinência número-pessoal. Se lembrarmos da distribuição inicial, apresentada na Fig. 1, teremos elementos suficientes para dizer que parece mesmo prematuro falar em extinção. A universalização da escola, tardiamente implantada nas últimas décadas do século XX no Brasil, poderia estar atuando no sentido de retardar ou mesmo de bloquear a mudança; obviamente, contudo, outro processo existente na língua parece se contrapor: a substituição de nós por a gente. Diante de tal complexidade, resta-nos reconhecer o muito que ainda há por fazer sobre a concordância de $\mathrm{P} 4 \mathrm{em}$ termos de estudo da língua falada na região e no país.

\section{CONCLUSÃO}

Neste trabalho apresentamos resultados parciais de um estudo sobre o uso de DNP-P4 nos dados do projeto VARSUL. Concentramo-nos na análise de entrevistas de Porto Alegre (capital) e Panambi (comunidade bilíngüe alemãoportuguês).

Este trabalho foi desenvolvido com o objetivo de testar algumas hipóteses sobre a DNP-P4, em especial, a que associa as formas não-padrão zero e -mo com menor escolaridade. Foi nosso objetivo, também, contribuir para a discussão acerca da caracterização da DNP-P4 como uma forma em extinção.

Sustentados pelo referencial teórico da sociolingüística quantitativa laboviana, pelos estudos prévios do português falado no Brasil (que postulam que se considere a concordância verbal como regra variável) e pelos estudos de gramaticalização (como processo diacrônico), foi-nos possível caracterizar a distribuição geral das variantes consideradas, mostrando, em primeiro lugar, que a DNP-P4 ainda parece bastante produtiva na amostra considerada.

Com relação à desinência zero, vale destacar que há evidências de que se concentre nos casos em que a forma verbal alvo é uma palavra proparoxítona, sancionada, de certa forma, por características prosódicas da língua. Outro resultado interessante relaciona-se com diferenças entre Panambi e Porto Alegre, sugerindo a necessidade de investigar melhor o papel do bilingüismo no uso da língua portuguesa naquela comunidade. Por fim, a relação entre posição do sujeito e desinência zero contraria expectativas de ordem funcional, ligadas ao caráter redundante ou não da informação contida no sujeito e na DNP-P4: ao que parece, em português, a concordância se estabelece preferentemente com o elemento que está adjacente à esquerda do verbo. ${ }^{15}$

${ }^{15}$ Essa tendência parece estar ligada à outra, de progressivo preenchimento da posição de sujeito e de 216 
No que se refere à forma não-padrão - $m o$, há evidências que favorecem a interpretação de mudança em curso: jovens e mulheres usam mais essa forma. Destacou-se, nesta análise, o emprego preferencial de vamo em lugar de vamos, o que pode estar relacionado com a gramaticalização deste verbo como auxiliar. Essa deve ser a razão para termos a terceira conjugação como favorecedora dessa variante. Em relação a isso, é necessário providenciar uma análise mais adequada.

Por fim, o resultado que mais se destacou foi, com certeza, o da variável escolaridade, significativa estatisticamente nas duas rodadas binárias e com resultados diferenciados na rodada ternária. A presença da DNP-P4 padrão (-mos) é claramente favorecida com o aumento da escolaridade.

Dentre as muitas limitações que deveriam ser mencionadas aqui, gostaríamos de reconhecer que não foi possível, ainda, investigar mais detidamente a questão do discurso reportado: em nossos dados, esse fator favoreceu o apagamento do /s/. Além disso, é indispensável reconhecer também que a amostra investigada é pequena e precisa ser ampliada. Nesse sentido, parece de grande interesse investigar a DNP-P4 em dados de aquisição da linguagem e, também, nos dados do Projeto NURC, coletados na década de 70, para compará-los com os dados do VARSUL, da década de 90; em particular, deverá ser interessante comparar entrevistas dos mesmos informantes do NURC recontatados pelo VARSUL. Essas análises, provavelmente, serão mais adequadas para discutir mudança.

Dando continuidade a este trabalho, pretendemos, primeiramente, acrescentar dados de informantes com ginásio e com $3^{\circ}$ grau, de Porto Alegre, para analisar a variável escolaridade com mais precisão. Pretendemos, também, refinar a análise dos fatores lingüísticos, especialmente no caso do apagamento do $/ \mathrm{s} /$, investigando mais detalhadamente os contextos em que ele ocorre. Além disso, dentre as possibilidades analíticas, parece-nos importante averiguar, se for possível, o papel da saliência fônica e do monitoramento estilística, entre outras variáveis ainda não implementadas.

\section{BIBLIOGRAFIA}

ASSIS, Rosa Maria. Variações lingüísticas e suas implicações no ensino do vernáculo: uma abordagem sociolingüística. Ilha do Desterro - Sociolingüística. Florianópolis, UFSC, n. 20, p.59-81, 1988.

BAXTER, Alan N. A contribuição das comunidades afro-brasileiras isoladas para o debate sobre a crioulização prévia: um exemplo do estado da Bahia. In: d'ANDRADE, Ernesto \& KIHM, Alain. (orgs.) Actas do colóquio sobre Ciroulos de Base Lexical Portuguesa. Lisboa, Edições Colibri, p.7-35, 1992.

vinculação estreita (adjacência) entre sujeito e verbo, nesta ordem. 
Transmissão geracional irregular na história do Português Brasileiro divergências nas vertentes afro-brasileiras. Revista Internacional de Língua Portuguesa, n.14, p.72-90, dez. 1995.

BORTONI-RICARDO, Stella Maris. Problemas de comunicação interdialetal. Tempo Brasileiro, Rio de Janeiro, n.78-79, p.9-32, jul-dez, 1984.

. The urbanization of rural dialect speakers. A sociolinguistic study in Brazil. Cambridge, Cambridge University Press, 1985.

CAMACHO, Roberto Gomes. Aspectos funcionais e estruturais da concordância verbal no português falado. Alfa, São Paulo, n. 37, p.101-116, 1993.

CAMARA Jr., Joaquim Mattoso. Erros de escolares como sintomas de tendências lingüísticas no português do Rio de Janeiro. In: ___. Dispersos. p. 35-46, 1972.

CASTILHO, Ataliba T. de. O Português do Brasil. In: ILARI, Rodolfo. Lingüística Românica. São Paulo, Ática, p.237-285, 1992.

- A gramaticalização. Estudos Lingüísticos e Literários, PPG-Letras e Lingüística, UNB, n. 19, p.25-64, mar.1997.

EMMERICH, C. A língua de contato no Alto Xingu; Origem, forma e função. Rio de Janeiro, UFRJ, 1984. Tese de Doutorado.

FARACO, Carlos Alberto. O tratamento você em português: uma abordagem histórica. Fragmenta. Curitiba, UFPR, n.13, p.51-82, 1996.

GUY, Gregory R. Linguistic Variation in Brazilian Portuguese: Aspects of the Phonology, Syntax, and Language History. Philadelphia, University of Pennsylvania, 1981. Tese de doutorado.

LABOV, William. The intersection of sex and social class in the course of linguistic change. Language Variation and Change, New York, v. 2, n.3, p.205254, 1990.

LIRA, Solange. Subject postposition in Portuguese. D.E.L.T.A., São Paulo, EDUC, v.2, n.1, p.17-36, 1986.

MAYA, L. Z., SILVA K. Q. \& Zilles, A. M. S. A concordância verbal com a primeira pessoa do plural na fala de Panambi e Porto Alegre. Livro de Resumos do XI Salão de Iniciação Científica da-Universidade Federal do Rio Grande do Sul. Porto Alegre, UFRGS, p.477-478, 1999.

NARO, A. J., GÖRSKI, E. \& FERNANDES, E. Change without change. Language Variation and Change, New York, v. 11, n.2, p.197-211, 1999.

PINTZUK, Susan. Varbrul version 2.5, 1988.

RODRIGUES, Angela C. S. Língua e contexto sociolingüístico; concordância verbal no português popular de São Paulo. Publicação do Curso de PósGraduação em Lingüística e Língua Portuguesa. Araraquara, UNESP- Campus de Araraquara, n. 2, p.153-171,1992.

OLIVEIRA E SILVA, Giselle Machline \& SCHERRE, Maria Marta Pereira. (orgs.) Padrões Sociolingüísticos. Rio de Janeiro, Tempo Brasileiro, Depto. de Lingüística e Filologia, UFRJ, 1996. 
SILVA, Maria Cristina Figueredo. Inovações morfológicas no português brasileiro. In: CABRAL, Loni Grimm \& GORSKI, Edair. (orgs.) Lingüistica e Ensino: Reflexões para a prática pedagógica da língua materna. Florianópolis , Insular, p.181-198, 1998.

TEYSSIER, Paul. História da Língua Portuguesa. São Paulo , Martins Fontes, 1997. 